\title{
The study of effect of sand cushion thickness and foundation pressure on earthquake response in the ground
}

\author{
Dongyi Pan \\ Huzhou Vocational and Technology College,Huzhou.Zhejiang.China \\ Email:51540571@qq.com
}

\begin{abstract}
Keywords: sand cushion; thickness; foundation pressure; earthquake response
Abstract. Our country is a place where earthquake frequently happens and where seismic area is widely distributed. With the progress of science and technology, the use of computers and so on, from home and abroad we have achieved great development for the research and application of shock absorption and isolation methods for building structures, but there are still a lot of problems to be solved.Especially our country is a big agricultural country and we still have many low-and medium-rise building .Method for setting sand cushion between foundation and soil ground is a practical method with the least cost to reduce or not amplify the impact of the earthquake on the ground and finally achieve the purpose of shock absorption and isolation.In the study of effect of sand cushion thickness and foundation pressure on earthquake response in the ground, some useful results are obtained..
\end{abstract}

\section{Introduction}

Shock absorption and isolation technology is a new strategy and new technology .The concept is clear, shock absorption mechanism is specific, and isolating effect is obvious.It is safe and reliable, suitable for different earthquake intensity anti-earthquake requirements of the structure. Compared with traditional building, the building with shock absorption and isolation device has great social benefits and economic benefits.

Sand cushion isolation refers to build a certain thickness, density and water content of sand cushion between the base and the foundation and foundation building to control the ground motion passing up the structure. it not only meets the building functionality, usability and safety requirements, but also ensures building not collapsed when the big earthquake is encountered so as to achieve the purpose of earthquake fortification.

\section{Earthquake motion soil effect}

The earthquake effect of the earthquake motion includes earthquake motion energy effect, earthquake motion path effect, earthquake motion soil effect. In terms of earthquake effect research of earthquake motion, soil effect is more prominent and its main contents ${ }^{[2]}$ are:

Under the condition of small or slight vibration, the soil is the range of small strain deformation . At this time, the bed rock often show a smaller vibration amplitude, higher frequency component, and a shorter duration of earthquake motion. In the contrast, the soil makes the ground vibration amplitue increased, lower frequency components increased and the duration also increased. With the increase of the soil layer thickness and degree of the weakness, the feature is particularly prominent. However under the condition of strong earthquake, the situation is more complicated.

Under large strain condition, the soil effect is more complicated. Often due to the nonlinear deformation of the soft soil layer, it results in a large number of seismic wave energy dissipation, which can make the ground earthquake motion amplitude decrease, which is the weak ground islation effect.

In the dynamic calculation of soil, in the frequency range of earthquake motion, the plastic energy dissipation of the foundation soil is independent of frequency but related to the strain amplitude. The greater of the strain amplitude, the greater of the plasic energy dissipation . 
Therefore, lay the vibration-absorptive material that has a certain damping such as a certain size sand cushion under the building foundation. When earthquake occurred, the plastic deformation of the sand cushion consumes part of earthquake wave energy to decrease the the earthquake wave energy that passing up to achieve the purpose of the earthquake absorption.

\section{Effect of sand cushion thickness and foundation pressure on earthquake response in the ground.}

It is very necessary to study the Effect of sand cushion thickness and foundation pressure on earthquake response in the ground according to soil effect of the earthquake motion.

In this paper, the SLRA module of Engineering site seismic safety evaluation software is adopted to the analysis of earthquake dynamic response to foundation soil layers.This module uses the equivalent linearization method of one dimension soil layer shear dynamic analysis to observe earthquake response of different depth of the soil layer.

The sand cushion thickness to the effect of earthquake response on the ground

With the earthquake simulation calculation of the effect to the earthquake response coming from the different thickness of the sand cushion, Shear wave velocity of the sand cushion is setted as $200 \mathrm{~m} / \mathrm{s}$, the thinkness of the sand cushion changed $0.5 \mathrm{~m}, 1.0 \mathrm{~m}, 1.5 \mathrm{~m}, 2.0 \mathrm{~m}, 3.0 \mathrm{~m}, 5$ profiles together in consideration of the practical situation of construction and economic and El Centro wave 、 Qian'an wave and Parkfield wave input, their peak acceleration adjusted as 200gal、100gal and $200 \mathrm{gal}$ and the result of the earthquake response is in the table 1, table2,table3. Caculation formular of the decreasing amplitude ratio, as shown in equation 1.

Decreasing amplitude ratio $=\frac{\mid \text { Input acceleration }|-| \text { Out acceleration } \mid}{\mid \text { Input acceleration } \mid} \times 100 \%$

Table 1 The earthquake response when the EL Centro wave input with different thickness of sand cushion

\begin{tabular}{|l|l|l|l|}
\hline \multirow{2}{*}{$\begin{array}{l}\text { The thickness of sand } \\
\text { cushion(m) }\end{array}$} & \multicolumn{2}{|l|}{ Maximum acceleration } & $\begin{array}{l}\text { Acceleration defense } \\
\text { maximum } \\
\text { acceleration }\end{array}$ \\
\hline Datum profile & Amax (gal) & $\mathrm{a} \%$ & 1308.28 \\
\hline 0.5 & 414.9 & & 1230.16 \\
\hline & 327.2 & 21.37 & 1230.73 \\
\hline 1.5 & 324.7 & 21.74 & 1224.51 \\
\hline 2 & 316.8 & 23.64 & 1200.46 \\
\hline 3 & 305.0 & 26.49 & 1128.57 \\
\hline
\end{tabular}

Table 2 The earthquake response when the Qian'an wave input with different thickness of sand cushion

\begin{tabular}{|c|c|c|c|}
\hline \multirow{2}{*}{$\begin{array}{c}\text { The thickness of sand } \\
\text { cushion(m) }\end{array}$} & \multicolumn{2}{|c|}{ Maximum acceleration } & \multirow{2}{*}{$\begin{array}{c}\text { Acceleration defense } \\
\text { maximum spectral } \\
\text { acceleration }\end{array}$} \\
\cline { 2 - 3 } & Amax (gal) & a\% & 377.68 \\
\hline Datum profile & -113.4 & 6.79 & 355.29 \\
\hline 0.5 & -105.7 & 6.17 & 357.34 \\
\hline 1 & -106.4 & 5.29 & 358.90 \\
\hline 1.5 & -107.4 & 4.67 & 360.53 \\
\hline 2 & -108.1 & 3.88 & 364.29 \\
\hline 3 & -109.0 & & \\
\hline
\end{tabular}

Table 3 The earthquake response when the Parkfield wave input with different thickness of sand cushion

\begin{tabular}{|l|l|l|l|}
\hline $\begin{array}{l}\text { The thickness of sand } \\
\text { cushion(m) }\end{array}$ & Maximum acceleration & $\begin{array}{l}\text { Acceleration defense } \\
\text { maximum } \\
\text { acceleration }\end{array}$ \\
\hline Datum profile & Amax (gal) & spectral \\
\hline 0.5 & 248.5 & & 708.02 \\
\hline 1 & 219.4 & 11.71 & 559.68 \\
\hline 1.5 & 217.1 & 12.63 & 568.54 \\
\hline 2 & 206.0 & 17.10 & 611.00 \\
\hline 3 & 189.0 & 23.94 & 632.79 \\
\hline
\end{tabular}


It can be seen from table 1, table 2 and table 3,the earthquake absorption effect of different thickness sand cushion is different when the EL Centro wave and Parkfied wave is input. The major trend is more thicker the sand cushion is, the better the earthquake absorption effect. However, when Qian'an wave is input, the earthquake absorption effect is not obvious but slightly reduced with the thickness increase of the sand cushion. In the case of the input Qian'an wave, the influence of the thickness of the sand cushion on the acceleration is not small, but in this paper, the shear wave velocity range is still small.It illustrated that in the case of Qian'an wave input, the influence of the thickness of the sand cushion on the acceleration is not strong, but in the shear wave speed range of the paper study it still have small earthquake absorption effect. Fig. 1 the relationship curve between the thickness of sand cushion and the maximum acceleration when Qian'an wave, El Centro wave, Qian'an wave, Park-field wave are input.figure 2, figure 3 and figure 4 are the acceleration responses of seperate profile when different earthquake wave is input and the thickness of the sand cushion layer is different. Th e accelration value in the figure is absolute value.

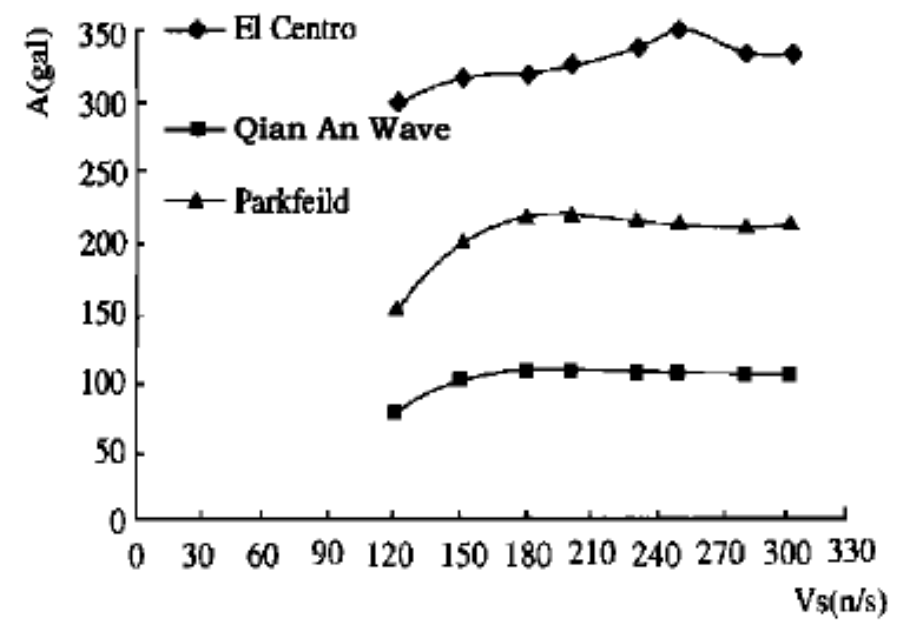

Fig. 1 Relationship between the thickness of sand cushion and the maximum acceleration

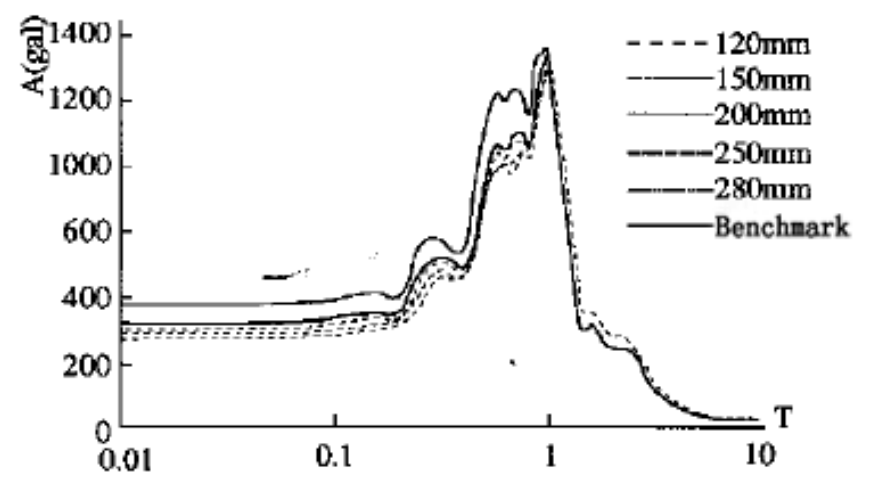

Figure 2 when the thickness of the sand cushion is different, the acceleration response spectrum (damping ratio 0.05, El Centro wave) 


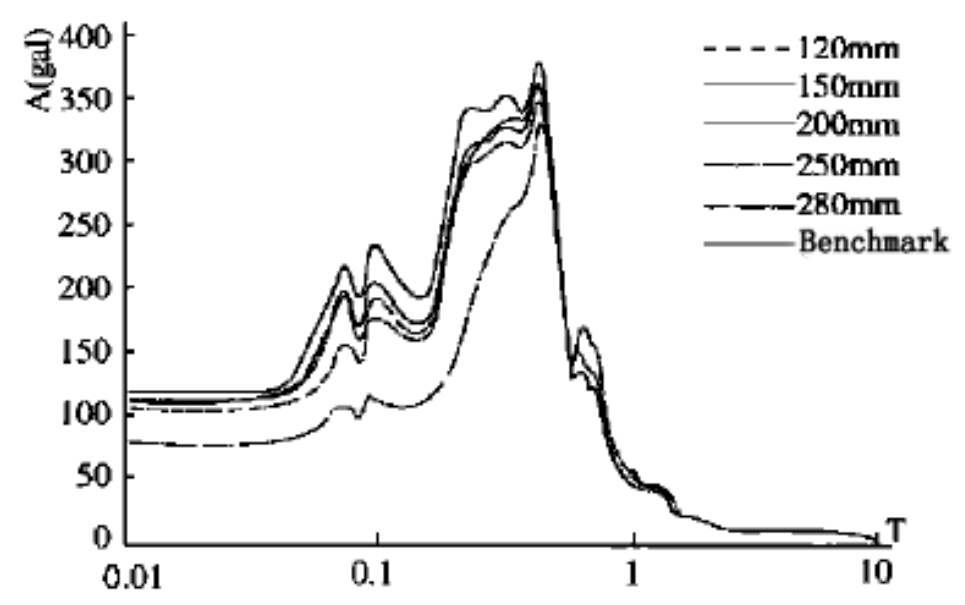

Figure 3. When the thickness of the sand cushion is different, the acceleration response spectrum (damping ratio 0.05, Qian'an wave)

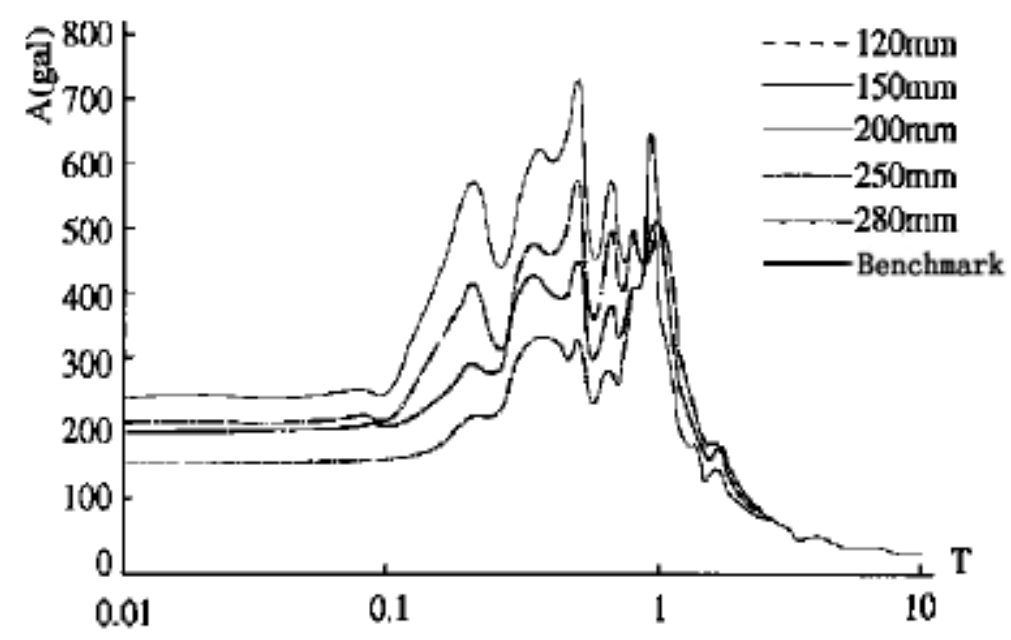

Figure 4. When the thickness of the sand cushion is different, the acceleration response spectrum (damping ratio 0.05, Parkfield wave)

\section{Conclusions}

(1) The effect of sand cushion thickness. The thickness of the sand cushion has 5 situations 0.5,1.0,1.5,2.0,3.0m. Calculation results show that: Compared with the corresponding results of the whole clay profile without sand cushion, while there are two kinds of earthquake response with sand cushion: The first is that the sand cushion has an obvious earthquake absorption effect and with the increase in the thickness of the sand cushion, the earthquake absorption effect is more obvious. This situation shows that the thicker of the sand cushion is, the more energy dissipation, the better the earthquake absorption effect will be. The other is the earthquake absorption effect of sand cushion is not obvious. These two situations are obviously related to the input of the Qian'an wave, the result of the first situation get s after the El Centro wave, Qian'an wave and Parkfield wave and artificial wave input while the other result from the other situation get after the Qian'an wave .It is known that the thickness of sand cushion does not play a major role in the earthquake absorption effect.

(2) Effect of base pressure on sand cushion. The base pressure in the calculation is 50, 100, 200KPA.The calculation results show that the earthquake response of the sand cushion under different base pressures is approximately the same. That is, it is independent of average pressure of the base. 


\section{Acknowledgements}

This work was financially supported by Huzhou Municipal Science and Technology Bureau in 2013. Projesct name is <Study on the technology of friction-sliding and disaster reduction of the foundation sand cushion in the village and town residence> (Project number:2013GY40).

\section{Reference}

[1] Xianhui Liu.Institute of Engineering, Mechanics.Earthquake Engineering and Engineering Dynamics.1988,8 (3)

[2] Bo Jiang, Sili Dai.Introduction to engineering seismology.Seismological Press.1993 